\title{
Reflection on the Deep Integration of Information Technology and Higher Education
}

\author{
Wenbin Liu ${ }^{\mathrm{a}}$, Jing Li ${ }^{\mathrm{a}}$, Gen Fan ${ }^{\mathrm{a}^{*}}$ \\ ${ }^{\mathrm{a}}$ Department of Basics, Wuhan Technology and Business University, Wuhan, China \\ *Corresponding Author: Gen Fan
}

Keywords: big data; information technology; teaching environment; deep integration

\begin{abstract}
Teaching informatization is a profound change in the field of education. Information technology is changing and even subverting the traditional educational teaching model, with the arrival of the era of internet. Firstly, there analyzes the characteristics of big data era and big data changes in education in the paper. Secondly, there defines the connotation of the deep integration of information technology and higher education in the era of big data. Thirdly, it points out the existing problems in the process of promoting the informatization of higher education. Finally, around the perfect environment, expanding the application, the depth of integration of the overall promotion strategy, there carries out active exploration and practice in the course of teaching information.
\end{abstract}

\section{Introduction}

With the development of mobile internet, mobile applications have a great influence on the teaching model of college education. Represented by mobile, social, cloud computing and big data analysis, a new wave of information technology is emerging rapidly. The traditional educational teaching mode has never been impacted. In the wave of information and digitalization, the field of education is undergoing a revolutionary change. While new information technology applications bring higher opportunities for higher education, higher education is also facing severe challenges. Higher education informatization is a cross combination of education and information technology, a realistic context to realize the deep integration of information technology and higher education, and also a strategic choice to realize the modernization of education[1]-[4]. From the university itself, we should attach great importance to and deeply understand the great influence of information technology on education. Informatization work is based on the basic task of talent training, actively explore the impact of information technology on education and teaching, explore how to change the teaching methods and learning methods by information technology, and strive to improve the quality of education and the quality of personnel training[5][6].

\section{Characteristics of big data era and educational change}

Big data refers to the inability to capture, manage, and process data sets within a given time scale using conventional software tools. Big data is the need for new processing mode in order to have more decision-making power, insight into the power of discovery and process optimization capabilities of massive, high growth rate and diversified information assets. The era of big data is 
the most prominent feature that the amount of data shows exponential growth trend, people's way of thinking and work will change, data mining, analysis and utilization has become the core of large data has become the motive force of educational innovation.

\subsection{Characteristics of big data era}

Typically, the "5V" feature presented in large data describes the characteristics of the big data age. "5V" is, Volume, Velocity, Variety, Value and Veracity .The core value of big data does not lie in big data, but what can be found from big data. Specifically for education, through the excavation and analysis of large data , the hidden associations, patterns and trends behind big data are discovered, in order to make decisions on education and teaching, analyzes the evaluation on the students and the needs of all the circumstances of the education and teaching.

\subsection{Big data impact on education and change caused}

In the era of big data, the way students acquire knowledge is not limited to the classroom. Online learning based on cloud computing will be the main way for students to acquire knowledge. The teaching style based on information technology will make personality education and lifelong education possible.This will lead to a major change in the educational model: (1)Big data promotes personalized self-learning.(2)Big data triggers changes in teaching morphology .(3)Big data calls for new learning environment and resources construction.(4)Online education leads to the borderless nature of university education.

\section{The basic idea of the deep integration of information technology and higher education}

The key to promoting the productivity of education is to realize the major structural change of the educational system under the support of information technology, rather than the progressive repair of the existing educational system structure. To realize the major structural change of the educational system, it is essentially a radical change in the structure of the classroom instruction in the college. The fundamental change of the classroom teaching structure mainly includes three aspects, namely, the creation of the information teaching environment, the innovation of teaching and learning, and the change of the traditional teaching structure in the classroom . In the current era of big data, compared with the traditional teaching mode, the flip classroom teaching mode has greatly changed from the classroom resource organization (micro class), teaching activity arrangement (flip) and teaching support environment (learning, analysis, support). The teaching activities translate into learning first, teaching later from teaching first, learning later. Extracurricula informal education has become the main battlefield of learning by yourself. Therefore, In the era of big data, essential connotation of the deep integration of information technology and higher education should reconstruct the ecological structure of college teaching around the change of ecological structure in classroom teaching, under the guidance of modern educational idea.

\section{Problems in deepening the informationization of higher education}

In recent years, many colleges and universities have embarked on the planning of information construction, the overall layout and step-by-step implementation, with remarkable results. The 
construction of infrastructure and hardware in colleges and universities has been greatly improved, which has promoted the rapid development of the informatization level of colleges and universities. But in general, the concept and level of information technology in universities need to be further improved, and the impetus and mechanism of informatization need to be further improved. The main problems lie in the following aspects:(1)The concept of educational informatization needs to be further deepened and improved.(2)There is a lack of effective supervision in the implementation of informatization.(3)The construction of digital learning environment is weak. (4)There are obvious defects in the construction of informatization team.

\section{The path of the deep integration of information technology and higher education}

In the era of big data, to carry out the deep integration of information technology and higher education, it is necessary to realize the reconstruction of macro and micro education ecology at the connotation level . From the point of view of the whole system theory, each element of the university teaching system is analyzed. Mainly from the concept of teaching, teaching environment, teaching resources, teaching team, teaching application and teaching elements of the system of overall planning of the college informatization construction, the development plan of educational informatization is included in the whole college's strategic development plan. Thus, the deep integration of information technology and higher education can be realized in the following aspects: renewing educational ideas, reforming educational system and innovating talents training mode, and innovating teaching contents, methods and means.

\subsection{Improve the environment, and effectively promote the depth of integration of information technology and teaching}

The development of information technology brings the "MOOK" phenomenon. The impact and challenge of the education system has a strong impact on the university. It mainly reflects in the impact of teaching value orientation and the impact of teaching mode,the challenge of passive teaching methods in repeating what the books say and cramming education, shaking the current teaching evaluation methods. The exchange of talents and competition in colleges and universities are more frequent and intense. It is more urgent for universities to speed up the reform of education and improve the quality of teaching. It needs to be based on the internationalization and modernization of universities. The thinking of global learning reconstructs the university running mode, co-ordinates the layout and paves the way for the future. The multimedia teaching terminal and network will be delivered to each classroom to realize the full coverage of the wireless network in the whole school teaching site and to build a campus ubiquitous learning environment. In addition, through the software service platform construction, there construct blended teaching support environment about teaching resource management and service, curriculum management and organization, Learning process tracking and evaluation. There explore innovative teaching mode. This truly promote the deep integration of information technology and teaching.

\subsection{To promote the curriculum system and promote the sharing of curriculum resources among colleges}

Curriculum teaching is the basis and core of talent training, and teaching informatization can not be divorced from curriculum. Institutions of higher learning should speed up the use of information 
technology to realize the reform of teaching mode, cooperate with and promote comprehensively with the fraternal institutions, and realize the sharing of resources. In the matter of the students cross elective, minor double degree and credit mutual recognition, the complementary teaching resources and joint talents training among institutions of higher learning is promoted, a framework of cooperation and practical programs is formed. The role of information technology is strengthened in teaching, quality, resource sharing and complementary advantages. In the aspect of depth union of talent training and training compound and innovative talents, the teaching informatization has opened up a new mode of cooperative education.

\subsection{To stimulate the enthusiasm of the teachers, to create a good environment of curriculum reform}

Teacher is the forerunner and practitioner of the teaching informatization, and the change of teacher's teaching idea and the mobilization of enthusiasm have a direct influence on the process of teaching informatization. Therefore, a more effective policy support and the teacher performance evaluation system about guaranteeing condition and teachers ' work, need be established, and this encourages teachers to join the teaching reform, chooses course characteristics and their own expertise in information technology and the curriculum integration, guides and motivates the teachers involved in teaching reform, selects the appropriate course characteristics and their own expertise in information technology and the curriculum integration. Teachers and teaching experts are recommended to participate in high level teaching and train at home and abroad and seminars. They are encouraged to preside over or participate in online curriculum construction, the leading role of teachers is played, and high quality courses are cultivated.

\subsection{The teaching evaluation system based on process management is gradually reconstructed}

It is necessary to establish a new mechanism for evaluating students' learning and evaluating teachers' teaching on the basis of online teaching platform. Taking the whole course of the students' participation in the course of teaching as an important content of the teacher evaluation of students, no longer simply on the merits of the performance, to stimulate the initiative of students learning, and enhance the overall quality and innovative ability of students. On the other hand, the evaluation results of the students to teachers as an important basis for teacher assessment and student course selection, encourage teachers to continue to develop high-quality resources, improve teaching quality.

\section{Conclusion}

Today's society has entered the information age, and cloud computing, Internet of things and the big data technology based on the two are driving a deep change in education. With the support of big data technology, higher education will be more personalized and humanized, and the teaching form will be closed and turned to open, which will make the boundary of formal education and social education disappear. Curriculum teaching informatization is an effective way to reform the teaching mode, realize the sharing of resources, and improve the quality of personnel training. We should recognize that information is a complicated system engineering, need to guide the concept of top-level design, promote leadership, collaborative efforts, security conditions in many aspects, and 
the information itself is a continuous development, continuous improvement, constantly upgrade process. In order to improve the quality of personnel training and explore the advantages of discipline resources, it is necessary to improve the quality of talent training and improve the enthusiasm of teachers to participate in curriculum construction, and to strengthen the cultivation and sustainable development of high-quality curriculum resources. At the same time, teachers need be encouraged to actively participate in teaching and personnel training, the transformation of teaching ideas need be promoted, teaching content need be updated and reform of teaching methods need be reformed, so as to further improve the competitiveness of colleges and universities under the trend of information technology and the quality of talent training.

\section{Acknowledgments}

This research was supported by special subject of educational informatization of Higher Education Society in China (Grant No. 2016XXYB22), the teaching reform Fund of educational commission of Hubei province in China(Grant No. 2016445), the teaching reform Fund of Wuhan Technology and Business University in China(Grant No. 2016Z07).

\section{References}

[1] KeKang He . How to realize the "deep integration" of information technology and education [J].Curriculum, Teaching Materials and Teaching Methods.2014(2):58-67.

[2] KeKang He . Learning "ten year development plan of educational informatization" - an interpretation of the deep integration of information technology and education[J]. Audiovisual Education in China,2012(12):19-23.

[3] Jing Lu. Application of interactive whiteboard in College Classroom Teaching[J]. Audiovisual Education in China,2011(13):83-85.

[4] Shaochun Zhong. An overview of the development of information technology and curriculum integration in the past ten years[J]. Information Technology Education in China.2010(21):11-13.

[5] Khalid,A.B.Barriers to the Successful Integration of ICT in Teaching and Learning Environments:A Review of Mathematics,Science \& Technology Education,2009(3):235-245.

[6] Ruben,V,Johan,V.B,\& Sara,D.ICT Policy Planning in a Context of Curriculun Reform:Disentanglement of ICT Policy Domains and Artifacts[J].Computers \& Education,2012(58):1339-1350. 